\title{
Hospedagem verde: práticas ambientais adotadas em hotel certificado pela ISO 14001
}

O presente trabalho compreende um estudo qualitativo que objetiva apresentar as principais práticas ambientais adotadas em um Hotel, situado em João Pessoa, Paraíba, na beira mar da praia de Manaíra. O empreendimento já surgiu com o intuito de ser sustentável e optou pela cidade litorânea, visto que na época da instalação era considerada a capital mais arborizada do Brasil. Na pesquisa foram consultados colaboradores da empresa que possuem cargos de gestor e analista, trabalham há mais de três anos e atuam no setor ambiental da mesma, apresentando conhecimento na temática. Além disso, também foi utilizado a técnica de observação in loco, visitas técnicas e consulta às mídias digitais que expõem informações precisas e contribuiu para o atendimento aos objetivos dessa pesquisa. Com base nas comunicações, visitas e coleta de informes, foi possivel perceber as atividades que são realizadas rotineiramente na organização, que são parte do seu programa de Gestão Ambiental. Constatou-se que o empreendimento insere na sua cultura a boa conduta ambiental, buscando engajar toda a empresa nesse propósito, assim como, hóspedes e comunidade. O hotel utiliza muitas ferramentas para respaldar as práticas ambientais dentro do empreendimento e viabiliza ao seu corpo funcional o preparo para atender a essa nova expectativa de mercado.

Palavras-chave: Práticas Ambientais; Gestão Ambiental; Sustentabilidade; ISO 14001

\section{Green lodging: environmental practices adopted in hotel certified by ISO 14001}

\begin{abstract}
The present work is a qualitative study that aims to present the main environmental characteristics adopted in a Hotel, located in João Pessoa, Paraíba, on the seaside of Manaíra's beach. The venture already appeared with the opportunity to be sustainable and opted for the coastal city, since at the time of installation it was a more wooded capital of Brazil. In the survey were consulted employees who hold positions of manager and analyst, with more than three years of experience and who work in the sector of the same, having knowledge in the area. In addition, an on-site observation technique, technical visits and digital media consultations were also used to present accurate information and contribute to the objectives of this research. Based on communications, visits and information gathering, it was possible to perceive what are the activities that are routine advertisements, which are part of its Environmental Management program. It was verified that the entrepreneur inserts itself in its culture as environmental, seeking to engage an entire company in the purpose, as well as, guests and community. The hotel has many tools to help you realize experiences within the enterprise and enable your staff the preparation to meet a new market expectation.
\end{abstract}

Keywords: Environmental Practices; Environmental Management; Sustainability; ISO 14001.

Topic: Gestão Ambiental e da Biodiversidade

Reviewed anonymously in the process of blind peer
Received: 16/10/2018

Approved: $\mathbf{1 1 / 1 2 / 2 0 1 8}$
Jéssica Morais Braga Lyra

Universidade Federal de Campina Grande, Brasil

http://lattes.cnpq.br/7808685574532794

jessicabragaadm@gmail.com

\section{Maria de Fátima Nóbrega Barbosa}

Universidade Federal de Campina Grande, Brasil

http://lattes.cnpq.br/8262057016878547

mfnbarbosa@hotmail.com
Referencing this:

LYRA, J. M. B; BARBOSA, M. F. N.. Hospedagem verde: práticas ambientais adotadas em hotel certificado pela ISO 14001. Revista Brasileira de Administração Científica, v.9, n.3, p.64-73, 2018. DOI: http://doi.org/10.6008/CBPC2179-684X.2018.003.0005 


\section{INTRODUÇÃO}

Muitas discussões e medidas vem ganhando notoriedade e mudando a maneira como o governo, as empresas e a população precisam lidar com as novas demandas para atender a economia, a política, o meio ambiente e a sociedade no geral. A inquietação com a degradação ambiental e a sua relação com as práticas de consumo e produção capitalistas começou a ser discutida com mais ênfase em meados da década de 1970 (JABBOUR, 2007).

Nesse sentido, é considerado que as empresas estão incluídas entre as causadoras dos danos ambientais, tendo em vista que no processo produtivo há forte tendência de consumo de recursos de bem comum, descartes inadequados, má gestão, entre outros fatores, que muitas vezes causam agravos ao meio ambiente. Deste modo, as corporações passam por alterações expressivas na conjuntura em que atuam, antes, eram vistas como apenas instituições econômicas, hoje estão cientes das novas funções que precisam desempenhar. A atenção de algumas corporações não está direcionada apenas para questões econômicas, a tendência é a melhor percepção para questões socioambientais. Esse tipo de mudança está ligado com as pressões que as partes interessadas estão impondo (DONAIRE, 2014).

O atual estágio da Gestão Ambiental se constitui em um processo evolutivo composto por um conjunto de fases, o qual é passível de implantação gradual mediante práticas apropriadas. Entre os modelos pioneiros de Gestão Ambiental, tem-se a ISO 14001, que foi baseado na abordagem de sistemas da qualidade. Podendo ser aplicado em quaisquer empresas e prevê a implementação de vários elementos para uma gestão eficaz (BARBIERI, 2007; EPELBAUM, 2004).

Partindo do contexto da crescente necessidade de analisar as questões socioambientais nas estratégias; decisões e ações organizacionais é relevante discutir e investigar acerca das reformulações que as empresas vêm praticando com o propósito de aprimorar seu gerenciamento. Desse modo, considerando a Gestão Ambiental como forma de melhorar o desempenho organizacional, esse estudo objetiva apresentar as práticas ambientais em um hotel situado em João Pessoa - Paraíba, que possui a certificação ISO 14001 . 0 empenho em concretizar o estudo está atrelado a expor os aspectos que deram certo, para disseminar as práticas e tornar público, servindo de exemplo para demais empresas que queiram adotar condutas ambientais e a para a sociedade que busca conhecimento nos temas em questão.

\section{REVISÃO TEÓRICA}

\section{Motivadores para implantação da Gestão Ambiental}

Os países começaram a entender que as medidas ambientais não impedem o crescimento econômico, contudo, há um intenso distanciamento entre as nações da Europa e da América Latina, onde nessa última há fortes índices de problemas sociais como: miséria, pobreza, corrupção e crescimento acelerado. Sendo esses fatores considerados como empecilhos para o desenvolvimento de condutas ambientais, por parte da sociedade. Todavia, com o advento das novas regulamentações e das leis, os governos (federal, estadual e municipal) e as empresas passam a modificar sua forma de exercer suas 
atividades, estando pressionadas a inserir novas formas mais rigorosas de proteção e conservação (DONAIRE, 2014).

As firmas precisam ser agentes de soluções acerca dos problemas planetários e não propulsoras de mais dificuldades. As preocupações ambientais dos empresários são impulsionadas por três forças que se relacionam reciprocamente, são essas: o governo, o mercado e a sociedade. Caso não houvesse pressões da sociedade e medidas governamentais, provavelmente, não se observaria o interesse das empresas para o quesito ambiental (BARBIERI, 2007).

Donaire (2014) ainda descreve que a mudança no ambiente de negócios é decorrida da consideração de novos aspectos. 0 modelo tradicional que era inserido nas empresas priorizava o caráter econômico, dentro de um ambiente previsível e estável, dando-se importância à ideia de que algo estimado como bom para as empresas, seria bom, também, para a sociedade de forma geral. Apesar disso, a visão moderna da empresa é mais complexa, abrangendo fatores sociais, haja vista a relevância de considerar o ambiente externo e as consequências advindas das atividades econômicas, que se continuar sendo concretizadas aos moldes antigos (sem atender o quesito socioambiental), provavelmente, resultarão em: deterioração física do ambiente e urbana, condições insalubres de trabalho, discriminação a alguns grupos sociais, entre outros contratempos.

As motivações para a adoção de um sistema de gestão ambiental são muitas, porém, os estudos apresentam que a legislação é um dos principais incentivos (ROSA et al., 2017). Já de acordo com o estudo de Alperstedt et al. (2010) os fatores externos determinantes para a busca da GA são: exigência da sociedade/clientes, governo, adequação a padrões normativos, tendência do mercado, obtenção de crédito e pressão de organizações ambientalistas. Para Gasi et al. (2006), as corporações passaram a considerar a variável ambiental em sua gestão, sobretudo, por influências de legislação, como do mercado.

A importância da Gestão Ambiental nas empresas foi enfatizada a partir de quando essas notaram que as soluções de engenharias não se equilibram se não fossem auxiliadas por estruturas organizacionais adequadas e eficazes, logo, é preciso haver estrutura no empreendimento. Sendo assim, as ferramentas e os modelos de Gestão, seja financeira, de processos e, nesse caso, ambiental, dão maior respaldo para uma administração assertiva (ELPEBAUM, 2004).

Nesse novo contexto de mudança de comportamento e prioridades, as empresas (principalmente as poluidoras), frente às novas práticas exigidas, determinam os rumos da Gestão Ambiental, sendo este caracterizando como a aplicação dos princípios de planejamento; avaliação; controle; monitoramento e redução dos impactos ambientais a níveis definidos (ELPEBAUM, 2004). Seiffert (2011) declara que conceituar a Gestão Ambiental abrange muitas questões estratégicas, que envolve uma visão holística. Para autora, três aspectos integram a Gestão Ambiental, sendo esses demonstrados a seguir:

Política Ambiental: Conjunto de princípios doutrinários que acordam ações aspirações sociais e governamentais regulamentam; Planejamento Ambiental: Estudo prospectivo que visa a adequação do uso, controle e proteção do ambiental. Por meio da coordenação e implantação de projetos que intervém 
estruturalmente ou não a organização; Gerenciamento Ambiental: É o conjunto de ações voltadas a controlar o uso, proteção e conservação do meio ambiente e avaliar a aplicação da política ambiental.

Muitas são as transformações que a gestão ambiental tem passado e há os autores que dividem essa evolução em etapas. Contudo, observam-se hoje empresas que atuam apenas com ações reativas, de controle da poluição com foco no cumprimento da legislação, enquanto outras realizam investimentos em novos produtos, processos e tecnologias inovadoras, com uma postura proativa em relação às questões ambientais (TRIERWEILLER et al., 2014).

\section{Sistema de Gestão Ambiental: ISO 14001}

Conforme Barbieri (2007), em suma, as empresas precisam ser agentes de soluções acerca dos problemas planetários, e não propulsoras de mais dificuldades. Portanto, entende- se que além de perceber o contexto interno e externo em que a companhia se insere, é importante estar preparado para enfrentar dispêndios e prejuízos que as atividades promovidas pelas próprias organizações possam ocasionar. Deste modo, gerir o negócio respaldando-se em modelos e ferramentas, permite uma direção mais assertiva e alcance de desempenho satisfatório, nesta vertente, a seguir serão expostos alguns métodos de Gestão Ambiental.

Em meio as principais estratégias indicadas para abordar os problemas ambientais estão os Sistemas de Gestão Ambiental (SGA), designados como direções para identificar e administrar os aspectos e os impactos ambientais gerados pelas empresas. O SGA está intensamente ligado aos sistemas de gestão da qualidade, possibilitando o controle daquelas tarefas que podem resultar em danos ao meio ambiente, buscando tornar mínimo os impactos ambientais de suas operações e o aprimoramento do desempenho dos processos. Muitas organizações estão utilizando normas de sistemas de gestão como ISO 14001, ISO 9001, entre outras, para atender as pretensões das partes interessadas e tornarem-se sustentáveis (ACUÑA et al., 2017; FERREIRA et al., 2016).

A ISO 14001 foi o modelo pioneiro de Gestão Ambiental, baseado na abordagem de sistemas da qualidade. Podendo ser aplicado em quaisquer empresas e prevê a implementação de dezoito elementos para uma gestão eficaz. Apresenta duas premissas: melhoria contínua do desempenho ambiental e a prevenção da poluição (EPELBAUM, 2004). A ISO 14001 foi criada em 1996 por influência dos debates ocorridos na Eco-92. É considerada como um padrão internacional que determina especificações para sistemas de gestão ambiental incluindo requisitos para a estrutura organizacional, práticas, processos, recursos, responsabilidades e procedimentos, com a finalidade de metodizar o sistema em uma organização (FERREIRA et al., 2016).

A implementação da ISO 14001 proporciona muitos benefícios para o crescimento dos mercados nacional e internacional, já que esta área da gestão é tão relevante quanto a gestão da qualidade, dessa forma é preciso identificar essas vantagens para uma melhor utilização. Quando adotado da forma adequada, permite que as empresas consigam maior eficiência e eficácia organizacional, por meio da redução dos custos e dos impactos ambientais (ACUÑA et al., 2017). 


\section{METODOLOGIA}

O trabalho em questão pode ser considerado como qualitativo, tendo em vista a intenção de analisar particularidades de modo subjetivo. Os estudos voltados para uma análise qualitativa têm como propósito abordar situações abrangentes ou completamente particulares. Pode apresentar complexidade de determinado problema, analisar a relação de certas variáveis, entender e considerar processos dinâmicos vivenciados por grupos sociais, colaborar na mudança de algum grupo e permitir a compreensão das peculiaridades do comportamento das pessoas (RICHARDSON, 2012).

No que se refere ao tipo de pesquisa, esta foi considerada como exploratória. A pesquisa exploratória possibilita maior familiaridade com o problema, tornando o mais explícito, objetiva o aprimoramento de ideias e descoberta de intuições. Em muitos casos, envolve o levantamento bibliográfico, entrevistas com pessoas que tiveram vivência com o problema de pesquisa e a análise de exemplos que estimulem a compreensão (GIL, 2011).

Para alcançar o objetivo optou-se pelo estudo de campo, sendo aplicado entrevista semiestruturada e observação não participante. O estudo de campo, conforme Gil (2002), verifica um único grupo ou comunidade (não necessariamente geográfica, podendo ser de trabalho, de estudo, de lazer ou outra atividade humana), ocorrendo a tendência em utilizar mais técnicas de observação do que de interrogação, podendo-se utilizar filmagens, fotografias, análise de documentos, entre outros.

O empreendimento estudado foi o Verdegreen Hotel, que está localizado em João Pessoa, Paraíba, à beira mar da praia de Manaíra. Foram realizadas duas visitas técnicas, uma para conhecer o ambiente e outra para ser feita uma entrevista com um colaborador da empresa. Além de coleta de informações in loco, também foram extraídas informações através das mídias do estabelecimento.

\section{RESULTADOS E DISCUSSÃO}

\section{Ecodesign}

O Hotel começou suas atividades em seis de dezembro de dois mil e dezoito já com a proposta ecológica em suas diretrizes, posto que construir uma empresa sustentável já era um sonho do proprietário. Como relatado a seguir pela entrevistada que acompanhou a segunda visita e forneceu as informações:

O Verdegreen já nasceu realmente para ser sustentável, foi sustentável desde o início. 0 Verdegreen é um sonho do dono, que o é gestor idealizador daqui do Verdegreen. Então, tudo isso nasceu de um sonho, ele sempre quis ter uma empresa sustentável com o nome Verdegreen. E aí, ele viu a melhor forma, o melhor negócio e surgiu o hotel. Só que o Verdegreen começou sustentável desde a obra a primeira gentileza urbana, que foi fazer o jardim e depois a construção. Ele já foi todo pensando para ser sustentável. Coleta seletiva, a obra $100 \%$ limpa. Existiam campanhas com as pessoas que faziam parte da obra, palestras de como ser sustentável, então, o prédio em si e toda a estrutura já nasceu sustentável, da iluminação natural à aquecimento da água (Entrevistada).

$\mathrm{Na}$ primeira visita técnica realizada ao Hotel, o colaborador mostrou as instalações do empreendimento, sendo estes: recepção, área da piscina, restaurante, elevadores, quartos, banheiros, auditórios, área restrita aos funcionários, horta, telas fotovoltaicas, garagem. Ele também apresentou como 
as ações ambientais seguidas funcionavam, contudo, foi uma explicação superficial para melhor entendimento. A pesquisadora não teve acesso, nem aprofundamento de muitos detalhes, tendo em vista que há aspectos que são restritos à empresa.

Verificou-se que no estabelecimento há uma predominância do Ecodesign na decoração do ambiente. Karlsson et al. (2006) descrevem que o ecodesing é um método de desenvolvimento de produtos que objetiva a diminuição do impacto ambiental e emprega a criatividade para originar novos produtos e processos mais eficientes em conformidade com a sustentabilidade. Para em Venzen et al. (2007), o ecodesing é uma iniciativa que deve ser tomada pelas empresas agora e no futuro. No Hotel foi visualizada essa prática diante alguns aspectos percebidos, a imagem abaixo é um exemplo do uso do ecodesign (Figura 01)

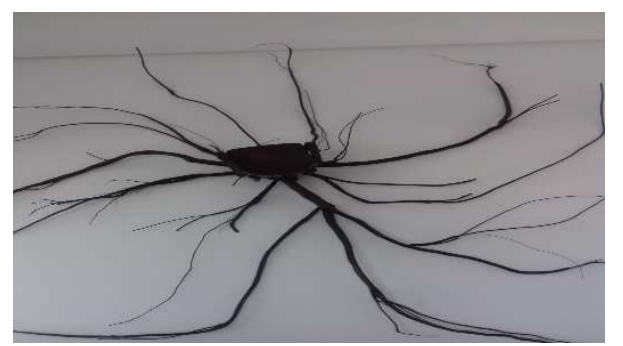

Figura 01: Item decorativo proveniente do Ecodesign (Incertae Sedis).

O item encontra-se no hall de entrada e pelo que foi notado, muitos hóspedes se atraem pela obra. Representa o aproveitamento de raízes de árvores modificadas e envernizadas e uma cadeira de escritório quebrada no meio, que se transformou em componentes, que antes estavam sem utilidade, para uma peça de decoração diferenciada e chamativa.

Segundo os relatos na visita técnica, o autor da arte é José Rufino, que além de artista e escritor, é professor de Arte nas universidades Federais da Paraíba e Pernambuco. Além do Ecodesign a composição para a ambientação do Hotel demonstra aspectos rústicos. A decoração foi executada por artistas regionais e locais como: José Altino (PB), Felismino (PB), Janete Costa (PE), José Guedes (CE), Expedito Seleiro (CE), José Paulo (PE) e Mestre Fida (PE). Onde demonstraram na forma de arte, características típicas da cultura nordestina. Essa valorização pela cultura da localidade representa o fortalecimento e uma responsabilidade socioambiental.

Em se tratando ainda da ambientação como parte das práticas ambientais, destaca-se que a estrutura do Hotel contém: revestimentos de cerâmicas naturais, uso da madeira de reflorestamento, valorização do artesanato local, iluminação de baixo consumo, sensores de presença, ar condicionado menos poluente de baixo consumo, elevadores inteligentes (que apresentam pequenas telas de computadores, onde são colocados informativos acerca do meio ambiente e economia dos recursos naturais).

\section{Energia Solar}

Matavelli (2013) expõe que a energia solar pode prover três tipos de processos: térmicos, elétricos e químicos. No Verdegreen foi visualizado o processo elétrico, que conforme o mesmo autor, essa ação (elétrica) consiste em procedimentos em que há a transformação direta em energia elétrica, como é no caso 
de tecnologias fotovoltaicas e geradores termoelétricos. Essa conversão de energia solar em energia elétrica se tornou uma alternativa muito viável, pois utiliza uma fonte de energia renovável. Deste modo, foi detectado que o Hotel faz uso desse recurso solar (Figura 02).
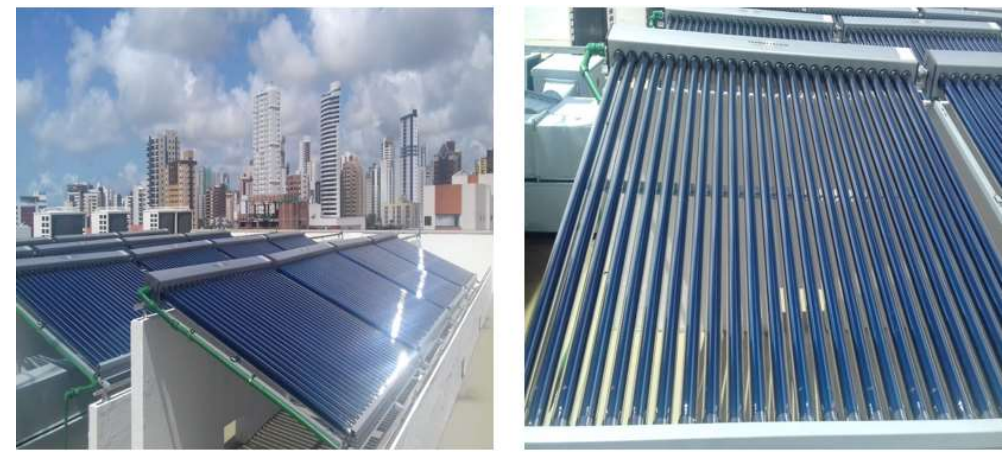

Figura 02: Placas solares.

Um dos problemas dos grandes centros é a falta de espaço, como não há espaço físico suficiente para a disposição de células fotovoltaicas nos grandes centros, uma opção foi a instalação desses painéis na cobertura de edifícios e sobre o teto de estabelecimentos (MATAVELLI, 2013). Portanto, no último andar, tem-se um espaço restrito, onde foram colocadas as placas solares fotovoltaicas.

Além de utilizar apenas a luz solar para gerar energia elétrica, os módulos fotovoltaicos não precisam ser localizados em áreas específicas, não geram ruídos durante o processo de conversão e podem ser acoplados em edificações (MATAVELLI, 2013).

Como essas placas transformam a luz advinda do sol em energia, para o hotel, a pretensão é usar a energia captada dessa fonte para fornecer o aquecimento dos chuveiros elétricos dos quartos. Antes, o modelo usado no Hotel eram as placas solares quadradas, contudo, a captação era menor. Hoje utilizam o mesmo espaço, só que o proveito é maior, já que em uma placa, têm-se 25 canos, assim, há uma capacidade maior para absorção da luz solar.

Ainda foi relatado que apesar da aquisição e utilização das placas, além de toda a estrutura colocada para fornecer o aquecimento aos chuveiros elétricos, houve queixas por parte dos hóspedes quanto ao uso dos chuveiros, posto que não estavam apresentando a temperatura mais quente ou morna, propicia para o banho de determinado usuário. A partir disso, o sistema foi revisto e novas placas mais modernas foram colocadas (como mostradas na imagem acima). Segundo o colaborador, esses investimentos foram realizados de modo recente. Ainda se tem a pretensão de instalar mais painéis solares.

Outra prática a ser destacada quanto ao uso do mesmo recurso natural para favorecer à economia de energia é a iluminação natural no hall. Ao entrar no hotel, o visitante se depara com a área social, que durante o dia é iluminada pela luz natural, proveniente das claraboias instaladas no teto. As claras boias, dispositivo envidraçado permite iluminação natural em um espaço interno. Sequencialmente, é evidenciada a imagem de uma parte do salão de entrada. Além desse ambiente, o restaurante, os corredores do térreo e dos três andares entre os quartos, os banheiros do térreo, durante o dia, não precisam de iluminação advinda da energia convencional. 


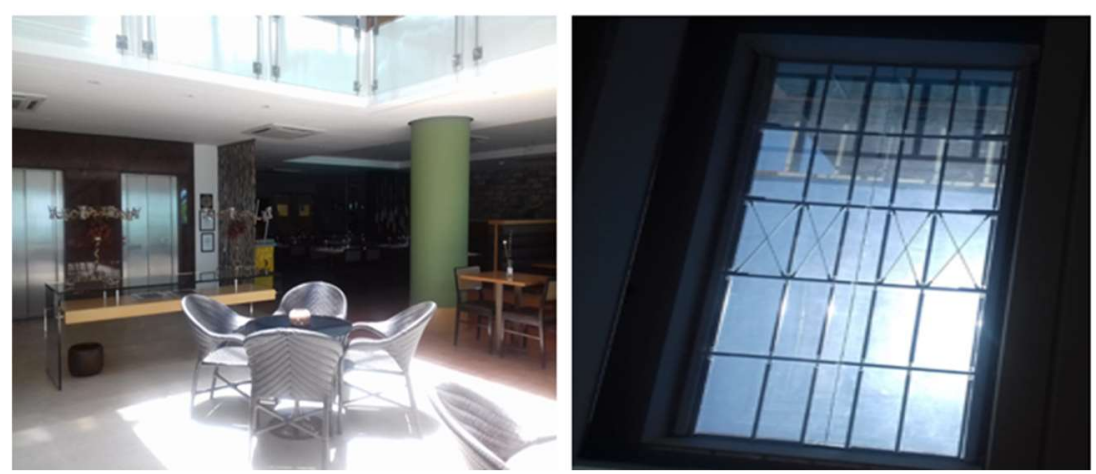

Figura 03: Hall de entrada.

\section{Gerenciamento dos Resíduos}

Outra prática observada nas visitas foi voltada para a coleta dos resíduos, onde se tem um trabalho, principalmente, com os colaboradores, para que esses possam realizar o descarte de forma apropriada. No ambiente restrito aos funcionários, têm-se os depósitos de lixos divididos para cada tipo de material. Além disso, têm-se placas com informações educativas, como forma de instruir e relembrar aos mesmos acerca dos seus deveres quanto a essas atividades.

A gestão seletiva do lixo ocorre em todo o hotel, inclusive nos quartos, todavia, essa prática não foi explanada minuciosamente na entrevista. Contudo, foi dito que o Verdegreen tem parceria com cooperativa da cidade e toda semana há um dia em específico que ela recolhe os resíduos que foram separados pelo hotel. Há um espaço físico apropriado para esse alojamento, com uma entrada exclusiva para a cooperativa colocar seu caminhão e recolher os resíduos. Como também, tem-se o local propício para depósito de resíduos.

\section{Auditorias ambientais}

A auditoria ambiental é uma forma de acompanhamento dos processos associados ao Sistema de Gestão Ambiental, onde há a monitoração. As auditorias procuram verificar se o SGA está de acordo com as diretrizes estabelecidas anteriormente. Dessa forma, é preciso que a organização esteja buscando detectar as não conformidades, para solicitar ações corretivas e preventivas, evitando desvios que podem vir a ocorrer (SEIFFERT, 2011). Na empresa estudada as auditorias são realizadas anualmente tanto internamente, como externamente, sendo um total de três auditorias, como mostrado abaixo:

Quadro 1: Relação de auditorias.

\begin{tabular}{|l|l|l|}
\hline \multicolumn{1}{|c|}{ Auditorias } & \multicolumn{1}{c|}{ Externa } \\
\hline Frequência & 2 vezes por ano & 1 vez por ano \\
\hline Data & 3 dias antes da data marcada, cada setor realiza ajustes & $\begin{array}{l}\text { A visita, data horário, são agendados com } \\
\text { antecedência. }\end{array}$ \\
\hline Duração & 1 dia/ 1 dia e meio & 2 dias/2 dias e meio \\
\hline Participantes & Todos os colaboradores & Todos os colaboradores e empresa certificadora \\
\hline Avaliadores & Supervisores & Organismo certificador \\
\hline
\end{tabular}

Primeiramente tem-se a interna, uma externa, que é realizada no meio do ano, e outra interna novamente. A auditoria interna verifica cada departamento e monitora as atividades e os requisitos a serem seguidos, sendo considerada como uma preparação para a auditoria externa feita pela certificadora. A 
externa, assemelha-se à interna, porém, terá uma averiguação mais crítica advinda de percepções de quem está fora do dia a dia da empresa. A entrevistada ainda colocou que buscam seguir todas as sugestões e condições propostas pela sua certificadora: BRUTV Avaliação da qualidade S.A., situada em São Paulo.

\section{Programas socioeducativos com hóspedes e colaboradores}

Segundo a colaboradora entrevistada, existem alguns programas/campanhas tanto com os funcionários, como com os hóspedes. Com os funcionários existem metas de redução para água, energia e resíduos e a cada mês é exposto para todos qual setor economizou mais, propositando o engajamento maior com a causa ambiental. Foi dito também que há a utilização de produtos de limpeza biodegradáveis e papéis reciclados

Percebe-se que há o estímulo por conhecimento através da "biblioteca compartilhada", onde os membros podem doar, trocar, alugar livros. Sendo realizados momentos com grupos para que determinado livro lido seja discutido entre eles e o conhecimento compactuado.

No que diz respeito ao trabalho educativo com hóspedes, esses podem cooperar com propostas de atividades e/ou práticas para o Hotel aplicar. Caso a ideia, advinda do visitante, seja acatada pela diretoria e aplicada, o hóspede ganha uma diária. Outra prática socioeducativa é a campanha transporte compartilhado, que se algum hóspede vai a determinado local mais distante, por exemplo, como o aeroporto, pode-se compartilhar a ida com algum outro visitante. Por fim, pode-se destacar, que no dia-a-dia, empresa também busca pelas seguintes técnicas: fornecedores a menos de $100 \mathrm{~km}$ de distância, conservação e manutenção de jardim público, apoio às iniciativas da WWF e de entidades voltadas para sustentabilidade sócio ambiental.

\section{CONSIDERAÇÕES FINAIS}

Diante do que foi discorrido, nota-se que a inserção da Gestão ambiental se apresenta como uma nova área que vem sendo incrementada nas empresas, principalmente, aquelas que buscam inovação e manutenção no mercado ou as que já se originam como o propósito de produzir e preservar o meio ambiente.

Percebe-se que o Hotel estudado busca realizar seus procedimentos, entre colaboradores, hóspedes, fornecedores e comunidade, enfocando o quesito ambiental, seja em processos internos ou externos. Seguir o sistema de Gestão Ambiental ISO 14001, possibilita ao Hotel executar suas tarefas de modo padronizado, estruturado, interligado e monitorado.

Pode-se destacar que o corpo funcional, sobretudo, deve estar apto a trabalhar sob essa nova perspectiva. Tendo em vista que a conduta consciente, o engajamento dos colaboradores e a preparação da empresa como um todo repercutirá no desempenho ambiental, social e financeiro.

Observa-se que a tendência da empresa é visar além das suas responsabilidades para com o cliente, inserindo em seus valores e suas atividades a responsabilidade socioambiental, seguindo, uma postura benéfica para a sociedade. As práticas encontradas nas visitas, a partir da pesquisa feita, pode servir de respaldo tanto para a comunidade empresarial, seja do ramo hoteleiro ou não. Como também, para demais estudos que busquem realizar um comparativo entre as empresas certificadas pela norma. 


\section{REFERÊNCIAS}

ACUÑA, N.; FIGUEROA, L.; WILCHES, M. J.. Influencia de los Sistemas de Gestión Ambiental ISO 14001 en las organizaciones: caso estudio empresas manufactureras de Barranquilla. Ingeniare, v.25, n.1, 2017.

ALPERSTEDT, G. D.; SOUZA, L. R.. Estratégias de gestão ambiental e seus fatores determinantes: uma análise institucional. RAE, v.50. n.2, 2010.

BARBIERI, J. C.. Gestão ambiental empresarial. São Paulo: Saraiva, 2007.

DONAIRE, D.. Gestão Ambiental na Empresa. São Paulo: Atlas, 2014.

EPELBAUM, M.. Gestão Ambiental Empresarial. São Paulo: Saraiva, 2007.

FERREIRA, C. S.; GEROLAMO, M. C.; Análise da relação entre normas de sistema de gestão (ISO 9001, ISO 14001, NBR 16001 e OHSAS 18001) e a sustentabilidade empresarial. Gest. Prod., São Carlos, v.4, n.23, 2016.

GASI, T.; FERREIRA, E.. Modelos e Ferramentas de Gestão Ambiental. São Paulo: Senac, 2006.

GIL, A. C. Como elaborar projetos de pesquisa. São Paulo: Atlas, 2002.

JABBOUR, C. J. C.. Contribuiç̧̃es da gestão de recursos humanos para a evolução da gestão ambiental empresarial: survey e estudo de múltiplos casos. Tese (Doutorado em Engenharia da Produção) -Universidade de São Paulo, São Carlos, 2007.

KARLSSON, R.; LUTTROPP, C.. Ecodesign: what's happening? An overview of the subject area of. Ecodesign and the papers in this special issue. Journal of Cleaner Production, v.14, p.1291-1298, 2006.

MATAVELLI, A. C.. Energia solar: geração de energia elétrica utilizandocélulas fotovoltaicas. Monografia (Graduação em Engenharia Química) - Universidade de Lorena, São Paulo, 2013.

NASCIMENTO, L. F.; VEZKE, C. S.. Modelos e Ferramentas de Gestão Ambiental. São Paulo: Senac, 2006.

RICHARDSON, R. J.. Pesquisa social: métodos e técnicas. São Paulo: Atlas, 2012.

ROSA, F.; FILHO, B. A. C.. Maturidade em gestão ambiental: revisitando as melhores práticas. Revista Eletrônica de Administração, v.2, n.15, 2017.

SEIFFERT, M. E. B.. ISO 14001 Sistemas de Gestão Ambiental: implantação objetiva e econômica. São Paulo: Atlas, 2011.

TACHIZAWA, T.; ANDRADE, R. O. B.. Gestão Socioambiental: estratégias na nova era da sustentabilidade. Rio de Janeiro: Elsevier, 2012.

A CBPC - Companhia Brasileira de Produção Científica (CNPJ: 11.221.422/0001-03) detém os direitos materiais desta publicação. Os direitos referem-se à publicação do trabalho em qualquer parte do mundo, incluindo os direitos às renovações, expansões e disseminações da contribuição, bem como outros direitos subsidiários. Todos os trabalhos publicados eletronicamente poderão posteriormente ser publicados em coletâneas impressas sob coordenação da Sustenere Publishing, da Companhia Brasileira de Produção Científica e seus parceiros autorizados. Os (as) autores (as) preservam os direitos autorais, mas não têm permissão para a publicação da contribuição em outro meio, impresso ou digital, em português ou em tradução. 